\title{
Problemas de COMPORTAMENTO DE CRIANÇAS/ ADOLESCENTES E DIFICULDADES DE PAIS/CUIDADORES: UM ESTUDO DE CARACTERIZAÇÃO
}

\author{
Alessandra Turini Bolsoni-Silva* \\ Mariana Marzoque de Paiva** \\ Caroline Garpelli Barbosa***
}

\section{Resumo}

Famílias que estimulam comportamentos socialmente habilidosos parecem favorecer o desenvolvimento social de seus filhos. Assim, intervir no relacionamento dos pais parece ser uma saída para minimizar indicativos de problemas de comportamento. Para uma efetiva intervenção é recomendado especificar as demandas das pessoas que procuram por atendimento, seja através da caracterização do repertório de pais e cuidadores, seja da caracterização das dificuldades e/ou habilidades das crianças e/ou adolescentes. O objetivo da pesquisa foi o de caracterizar, através de uma Entrevista Clínica Semiestruturada, queixas e dificuldades de 59 pais/cuidadores que buscaram atendimento psicológico em um Centro de Psicologia Aplicada. Os resultados principais são: a) queixas de problemas externalizantes, tais como agressividade, desobediência e birras; b) dificuldades dos pais/ cuidadores quanto às habilidades envolvidas no estabelecer limites (bater e não ter consistência) e na comunicação. Discute-se a interdependência entre os comportamentos dos adultos e crianças/adolescentes e repercussões para futuras intervençôes.

Palavras-chave: caracterização; habilidades sociais; problemas de comportamento.

\section{Abstract}

BEHAVIOR PROBLEMS IN CHILDREN/ADOLESCENTS AND DIFFICULTIES FOR PARENTS/ CARETAKERS: A CHARACTERIZATION STUDY

Families that stimulate social skills behaviors seem to favor their children's social development. Thus, to intervene in the parents' relationship seems to be a means to minimize

* Doutora em Psicologia. Universidade Estadual Paulista (Bauru).

** Psicóloga. Universidade Estadual Paulista (Bauru).

*** Psicóloga. Universidade Estadual Paulista (Bauru). 
certain behavior problems. For an effective intervention it is recommended to characterize the demands of individuals that seek assistance, be it through the characterization of the parents' caretakers' behaviors, as well as through the characterization of the children'sladolescent's skills andlor difficulties. The objective of the research was to characterize, through a Semi-structured Clinical Interview, complaints and difficulties of 59 parents/caretakers that looked for psychological assistance in a Center of Applied Psychology. The main results are: a) complaints of externalizing problems, such as aggressiveness, disobedience and obstinacies; $b$ ) difficulties of the parents/caretakers regarding the skills involved in establishing limits (to beat the child/ adolescent and not have consistency) and in communication. This paper discusses the interdependence between the adults' behaviors and the ones exhibited by children/adolescents and repercussions for future interventions.

Keywords: characterization; social skills; behavior problems.

Dificuldades de interação social, a partir de déficits em habilidades sociais e de consequentes interações coercitivas e/ou negligentes, são muito identificadas nas interações estabelecidas entre as pessoas no geral, o que não é diferente no caso do relacionamento estabelecido entre pais e filhos.

Muitas são as definições de habilidades sociais encontradas na literatura. De acordo com Caballo (1996), o comportamento socialmente habilidoso ocorre quando o indivíduo consegue expressar atitudes, sentimentos (positivos e negativos), opiniốes e desejos, de maneira que possa respeitar a si próprio e aos outros, para que possa existir, de uma maneira geral, resolução de problemas imediatos de uma determinada situação e consequente diminuição de problemas futuros.

Mais recentemente, Del Prette e Del Prette (2001) classificam e definem interações sociais a partir de respostas habilidosas, não habilidosas passivas e não habilidosas ativas (agressivo). No caso do relacionamento pais-filhos, BolsoniSilva e Marturano (2006) identificaram habilidades que parecem maximizar interaçôes positivas, às quais denominou-se Habilidades Sociais Educativas Parentais, referindo-se a habilidades sociais aplicáveis às interações pais e filhos (Silva, 2000). Bolsoni-Silva e Marturano (2002) afirmam que para os pais promoverem comportamentos socialmente habilidosos em seus filhos é necessário que se comportem maximizando as interaçôes sociais positivas, como, por exemplo, comunicando-se, sendo afetivos, sendo consistentes, dizendo não com explicação, resistindo a pressões e elogiando comportamentos socialmente habilidosos. Diante de comportamentos problema seria interessante, por outro lado, que os pais utilizassem algumas estratégias para estabelecer limites sem serem agressivos, tais como expressarem sentimentos negativos e positivos, apontando a quais comportamentos se referem, além de expressarem opinião e de pedirem mudança específica de comportamento e, assim, sinalizarem possíveis conse- 
quências positivas frente à mudança comportamental dos filhos (Bolsoni-Silva \& Marturano, 2002).

O desenvolvimento dessas habilidades sociais educativas dos pais pode ajudar na prevenção de problemas de comportamento das crianças, visto que, como apontam diversos autores (Bolsoni-Silva \& Del Prette, 2002; Bolsoni-Silva, 2003; Bolsoni-Silva \& Del Prette, 2003; Bolsoni-Silva, Del Prette \& Oishi, 2003; Cole, Zahn-Walser \& Smith, 1994; Cowan, Cohn, Cowan \& Pearson, 1996; D’ÁvilaBacarj, Marturano \& Elias, 2005; Jouriles \& Norwood, 1995; Kilgore, Snyder \& Lentz, 2000; Marinho \& Silvares, 1996; Marturano, Parreira \& Benzoni, 1997; Rosa, Garcia, Domingos \& Silvares, 2001; Weber, Prado, Viezzer \& Bandenburg, 2004), problemas de comportamento estão direta e/ou indiretamente relacionados ao repertório comportamental dos pais.

Nesta direção, Romero (1995) afirma que famílias de crianças com problemas de comportamento são caracterizadas por maior desorganização, mais problemas emocionais ou de comunicação e apresentam comportamentos e modelos “indesejáveis" para o desenvolvimento social e cognitivo das crianças. Mais especificamente, tais famílias parecem estimular esses comportamentos por disciplina inconsistente, pouca interação positiva, pouco monitoramento e supervisão insuficiente das atividades das crianças (Brioso \& Sarria, 1995; Conte, 1997; Kaiser \& Hester, 1997; Kaplan, Sadock \& Grebb, 1997; Patterson, DeBaryshe \& Ramsey, 1989; Webster-Stratton, 1997). Ainda de acordo com esses mesmos autores, muitos pais tendem a não reforçar positivamente os comportamentos socialmente habilidosos de seus filhos e punem, de forma pouco efetiva (não contingente, inconsistente), os comportamentos problema dos mesmos. Esta prática pode levar ao fortalecimento de respostas coercitivas emitidas pela criança ou adolescente, enquanto que as socialmente habilidosas são ignoradas ou consequenciadas de forma inapropriada.

As práticas parentais podem fazer elo com o campo teórico-prático do Treinamento em Habilidades Sociais, no que se refere às práticas parentais positivas, entendidas por Gomide (2006) como as que envolvem monitoria positiva (uso adequado da atenção e distribuição de privilégios) e o comportamento moral (o qual implica, por exemplo, promover condições favoráveis ao desenvolvimento das virtudes, tais como empatia, senso de justiça, responsabilidade e trabalho). As práticas educativas negativas envolvem, por outro lado, a negligência, ausência de atenção e de afeto e disciplina relaxada que compreende, entre outros aspectos, o afrouxamento das regras estabelecidas e a punição inconsistente.

E quanto à definição de problemas de comportamento, por não haver consenso na literatura (Bolsoni-Silva \& Del Prette, 2003), neste trabalho será utilizada a definiçãa funcional de Bolsoni-Silva (2003), na qual os problemas de com- 
portamento "seriam aqueles que dificultariam o acesso da criança a novas contingências de reforçamento, que por sua vez facilitariam a aquisição de repertórios relevantes de aprendizagem" (Bolsoni-Silva, 2003: 10).

Por entender que além da funcionalidade a topografia de resposta também é importante, considera-se a classificação de Achenbach e Edelbrock (1979), que identificam duas amplas categorias de problemas de comportamentos: os comportamentos externalizantes e os internalizantes. Os primeiros são aqueles que envolvem impulsividade, agressão, agitação, bem como provocações e brigas. Já os internalizantes podem ser observados quando há preocupação em excesso, tristeza, timidez, insegurança e medos. Ambos conjuntos de comportamentos podem trazer dificuldades de interação da criança com seus pares e adultos de sua convivência por dificultar o seu acesso a novas contingências de reforçamento e consequente redução de possibilidades de expansão de repertórios. Por exemplo, ao ser tímida, a criança pode perder a chance de tirar dúvidas com a professora ou de inserir-se em turmas de amigos e, por outro lado, se for agressiva, pode ficar isolada na escola e/ou na família, o que é fator de risco para aproximar-se de grupos desviantes. Tais relaçôes também denotam as dificuldades da escola e da família, em particular, em estabelecer contingências mais promotoras de habilidades sociais para as crianças e adolescentes.

Intervenções junto a pais e mães têm sido eficazes em diversos casos de problemas de comportamento. A orientação de pais possibilita equipá-los com habilidades necessárias para lidar com as dificuldades da criança (Dishion \& Andrews, 1995; Pfiffner \& McBurnett, 1997; Rosa, Garcia, Domingos \& Silvares, 2001; Ruma, Burke \& Thompson, 1996; Sanders, Markie-Dadds, Tully \& Bor, 2000; Webster-Stratton, 1997).

Para uma efetiva intervenção torna-se importante caracterizar as pessoas que procuram pelo atendimento, seja através da caracterização dos comportamentos dos pais, seja através da caracterização dos comportamentos das crianças/adolescentes, a fim de permitir a elaboração de estratégias mais condizentes com a população atendida.

Marinho e Silvares (1996) concordam que dados obtidos em estudos como esse podem auxiliar tanto em intervenções para reduzir problemas de comportamento, como para aquelas que buscam prevenir o surgimento dessas dificuldades. Poucos foram os estudos de caracterização realizados com a mencionada população, porém todos indicam a incidência alta de dificuldades interpessoais em crianças e adolescentes (Achenbach \& Edelbrock, 1979; Graminha, 1994; Santos, 1990), o que justifica a preocupação com intervenções o mais cedo possível, com os filhos e, especialmente, com suas famílias. 
Diante da literatura apresentada encontra-se uma lacuna no conhecimento no que se refere a caracterizar repertórios de pais e filhos quanto às queixas que motivam a procura por atendimento, ao menos na realidade brasileira, pois são escassos os estudos nessa direção. Consequentemente, o objetivo do presente artigo é o de caracterizar, através de uma Entrevista Clínica Semiestruturada, as queixas de um grupo de pais/mães/educadores que buscaram o serviço de atendimento psicológico em um Centro de Psicologia Aplicada (CPA), nos anos de 2004 a 2006, com a intenção de melhorar a relação estabelecida com seus filhos.

\section{MéTodo}

PARTICIPANTES

Participaram do estudo 59 pais/mães/cuidadores que buscaram o serviço de atendimento em um Centro de Psicologia Aplicada (CPA) de uma universidade do Estado de São Paulo, com a intenção de melhorar as interações com seus filhos. Os participantes tinham idades variando de 20 a mais de 50 anos (média = 35 anos), com baixa escolaridade (10 Grau) e também baixa renda familiar (variou de um a sete salários mínimos, com média de $\mathrm{R} \$ 1.200,00)$.

\section{INSTRUMENTOS}

a) Roteiro de Entrevista Clínica Semiestruturada, que sinaliza assuntos e tipos de perguntas abertas e/ou fechadas que auxiliam no levantamento de dados sobre queixas e variáveis relacionadas. Conforme as respostas dessas perguntas, implementam-se outras questôes que complementam as primeiras. As perguntas auxiliam os pais a exemplificarem suas dificuldades e os problemas de comportamento das crianças e/ou adolescentes, bem como favorece descrever antecedentes e consequentes. O tempo de duração de cada entrevista foi, em média, de 60 minutos, e elas foram gravadas por completo, a partir de uma autorização de cada participante que assinou um termo de consentimento livre e esclarecido.

\section{Perguntas NoRteAdoras DA ENTREVISTA (BOLSONI-SILVA, BITONDI \& MARTURANO, 2008)}

1. "O que te fez pensar em procurar o grupo?"

- se esta pergunta levar à descrição da queixa, buscar coletar mais dados por meio de exemplos de situações, frequência com que ocorrem, desde quando ocor- 
rem, tentar identificar situações antecedentes e consequentes do comportamento problema descrito pelo participante.

- se esta pergunta não levar à descrição da queixa, pedir que o cliente fale um pouco do seu relacionamento com seu filho(s), sobre suas maiores dificuldades com ele(s), sobre o que já tentou fazer para solucionar seus problemas e pedir exemplos de situações. Em seguida, busca-se, como no item anterior, identificar a frequência destes comportamentos-queixa, seus antecedentes e consequentes.

2. "Você já participou de algum atendimento psicológico?"

- se sim, identificar quando ocorreu, a frequência, quais as dificuldades na época.

3. "Você já participou de algum atendimento psiquiátrico?"

- se sim, identificar quando ocorreu, a frequência, quais as dificuldades na época. E também se houve a ingestão de algum medicamento, se sim, qual, por quanto tempo.

\section{PROCEDIMENTOS DE COLETA DE DADOS}

Os dados foram colhidos na clínica-escola da universidade, em sala livre de ruídos e de interferências. As entrevistas foram gravadas após autorização dos participantes. Essa entrevista é parte de um procedimento de avaliação que envolve a aplicação de outros três instrumentos, cujos dados permitem elaborar objetivos de intervenção a serem atendidos no treinamento subsequente. Portanto, esse trabalho é parte de um projeto maior, sendo resultado do primeiro contato com os participantes que buscam pelo atendimento junto ao CPA. O trabalho conta com a aprovação do Comitê de Ética em Pesquisa da universidade em que foram colhidos os dados.

\section{PROCEDIMENTOS DE TRATAMENTO E DE ANÁLISE DOS DADOS}

Após a coleta, as entrevistas foram transcritas e seu conteúdo analisado no que concerne às queixas/dificuldades dos filhos, bem como dos pais, mães e/ou cuidadores. Foram realizadas categorizações dos comportamentos mais frequentes presentes nos relatos dos participantes, sendo que as categorias criadas foram separadas no que diz respeito às queixas com relação aos comportamentos das crianças e com relação às dificuldades dos pais. Os comportamentos relatados com maior frequência foram agrupados dentro de uma mesma categoria e, em seguida, identificaram-se os antecedentes e consequentes das respostas apontadas 
pelos participantes. Tais informações permitiram hipotetizar sobre a função dos comportamentos relatados.

\section{REsultados}

Essa seção é iniciada com a descrição das categorias de problemas de comportamento apresentadas pelos filhos a partir do relato de seus pais ou responsáveis e, na sequência, encontram-se as suas queixas e dificuldades em relação à educação dos filhos. Finalmente são apresentados os dados referentes às condições antecedentes e consequentes.

\section{QUEIXAS SOBRE OS COMPORTAMENTOS DOS FILHOS}

A Tabela 1 (ver em anexo) apresenta os comportamentos das crianças/adolescentes, os quais foram agrupados em três categorias: a) externalizantes - criança é agressiva, desobediente, solicita atenção, faz birra e chantagem, conta mentiras e tem comportamentos autolesivos; b) internalizantes - tem medo, não quer comer, não quer ir à escola, rói unha, tem dificuldades interpessoais, de atenção e sofre de depressão; c) outros comportamentos - criança tem dificuldade de atenção na escola e criança tem comportamentos incompatíveis com a idade.

Os resultados apontam 73 queixas externalizantes trazidas pelos 59 participantes, sendo que as três mais frequentes são: "criança é agressiva" (n=28); "criança desobedece às ordens dadas pelos pais" ( $n=21)$; e "comportamento de birra" $(n=9)$. Os dados mostram que $14 \%$ dos comportamentos de agressividade das crianças ocorrem diante de outras crianças e adultos, sendo que, diante dessas circunstâncias, 17\% dos pais/mães/cuidadores repreendem ou brigam com seus filhos. Os comportamentos de desobediência geralmente aparecem diante de pedidos dos pais (76\%), que, em 38\% das situações, brigam e/ou batem em seus filhos após tais comportamentos. Já os comportamentos de birra das crianças ocorrem 34\% diante de um pedido negado pelos pais/mães/cuidadores. Nestes casos, após a birra, 34\% dos pais/mães/cuidadores acabam por ceder aos apelos da criança, atendendo-lhe o pedido.

A categoria de comportamentos internalizantes apresenta 29 queixas, sendo as mais frequentes: "criança tem medo" $(n=9)$; "filho solicita atenção equivalente à despendida ao irmão" ( $n=7)$ e "criança tem dificuldades de atenção na escola" $(\mathrm{n}=4)$. Com relação à categoria "criança tem medo", os resultados mostram que $50 \%$ dos pais que apresentam esta queixa relatam que esta ocorre diante de aulas de esportes, jogos de competição, hora de ir à escola, festas de aniversário, escola 
e locais com crianças desconhecidas. No que diz respeito às consequências frente ao medo dos filhos, $50 \%$ dos pais/mães/cuidadores fazem a vontade da criança e os demais encorajam o filho ou pedem para um irmão permanecer com a criança. Observa-se que os comportamentos que compõem a categoria "filho reclama atenção equivalente dos pais despendida aos irmãos" geralmente ocorrem quando os pais/mães/cuidadores brincam, conversam, cuidam e oferecem atenção e carinho a um dos irmãos (57\%). Diante das reclamações das crianças, os pais: conversam com a criança $(57,2 \%)$ e negam o que o filho diz $(42,8 \%)$. Dos pais/mães/ cuidadores que relatam que seus filhos "têm dificuldades de atenção na escola", $50 \%$ relatam que tais comportamentos ocorrem quando os filhos estão diante de atividades escolares, como ter que fazer a tarefa de casa, ou mesmo na própria escola. Diante dessas circunstâncias, 25\% dos pais/mães/cuidadores procuram conversar com o filho e explicar a importância dos estudos.

\section{QUEIXAS/DIFICULDADES ACERCA DO PRÓPRIO REPERTÓRIO COMPORTAMENTAL}

Em relação às dificuldades identificadas pelos participantes, os resultados apontam a frequência de 107 comportamentos não habilidosos ativos dos pais, sendo a categoria mais frequente "pais/cuidadores gritam e/ou batem quando o filho emite comportamentos 'indesejáveis'” $(\mathrm{n}=33)$. Há 22 relatos de comportamentos não habilidosos passivos e 9 outros comportamentos não habilidosos. As queixas/dificuldades dos pais/cuidadores mais citadas são: "pai e mãe não concordam com relação à educação dos filhos" ( $\mathrm{n}=21)$; "falta de consistência da mãe/pai/cuidador diante dos comportamentos da criança" ( $n=12)$; "dificuldade em conversar/comunicação com a criança" ( $n=10)$; "não gosta que o filho brinque na rua e/ou na casa de amigos" ( $n=9$ ); e "dificuldades em estabelecer limites” $(n=8)$. De acordo com as categorias já citadas, a maioria dos pais/cuidadores queixa-se dos comportamentos externalizantes das crianças, tais como "criança é agressiva", "criança não obedece ordem dada". As consequências mais frequentes diante de comportamentos externalizantes das crianças são os comportamentos "não habilidosos ativos" dos pais/cuidadores $(\mathrm{n}=28)$, em seguida, os "comportamentos habilidosos" ( $n=5)$ e, por último, os "comportamentos não habilidosos passivos" ( $\mathrm{n}=4)$.

A seguir é descrita a categoria mais frequente no que diz respeito aos comportamentos não habilidosos ativos $(\mathrm{n}=28)$. No que se refere aos antecedentes desses comportamentos, as categorias mais frequentes são: "Criança desobedeceu a uma ordem dada" ( $\mathrm{n}=18)$; "Criança emite comportamentos agressivos" $(\mathrm{n}=14)$; "Criança faz pedido" $(\mathrm{n}=18)$. Enquanto que os consequentes apresenta- 
dos com mais frequência dos comportamentos não habilidosos ativos são: "Criança chora, fica com muita raiva e muito nervosa" $(n=13)$ e "Cônjuges discutem" $(\mathrm{n}=7)$.

Além dos comportamentos não habilidosos ativos expressos pelos pais quando eles se relacionam com seus filhos, os participantes da pesquisa também revelaram comportamentos não habilidosos passivos $(n=5)$ durante interação com as crianças. Frente a algumas situações de conflitos, os pais se comportam não interferindo nas respostas das crianças, como, por exemplo, ignorar, sair de perto, não fazer/falar nada, ora sendo inconsistentes frente aos comportamentos das crianças, ora com dificuldade em conversar com seus filhos.

As queixas mais frequentes são as de "dificuldades em estabelecer limites" aos comportamentos das crianças $(n=8)$. Os pais reclamam que nessas situações sentem-se estressados/contrariados/frustrados $(n=4)$ devido a não saberem como agir diante dos comportamentos dos filhos do cotidiano: comer, dormir, tomar banho, ir à escola, etc.

As outras categorias apresentadas com menor frequência são: "dificuldades em manter o autocontrole" ( $n=7)$ e "reforçar comportamentos que julgam inadequados" ( $\mathrm{n}=7$ ) do filho; neste último, os dados apontam que os comportamentos inadequados são, na maioria das vezes, pedidos supérfluos ou desobediência de ordem seguida de choro; as consequências nesta categoria de respostas em que os pais reforçam o que julgam inadequado são sentimentos de frustração em relação à condição de autoridade de pai $(n=1)$ e alívio imediato porque o choro ou a "arte" que a criança faz é interrompida no mesmo instante $(n=3)$. A dificuldade de manter o autocontrole $(n=7)$ acontece desde em situações ditas pelos próprios entrevistados como extremas - o filho diz que a mãe não gosta dele $(n=1)$, criança afirma que deseja a morte da mãe $(n=1)$, filho quer saber acerca da dependência química do pai $(n=1)$ - até em fatos corriqueiros, como, por exemplo, o não cumprimento de tarefas domésticas $(n=1)$ e dificuldades da criança na escola $(n=1)$. Em relação às "dificuldades em dizer não" $(n=4)$, todos os participantes disseram que isso ocorre sempre diante de um pedido do filho, dois deles disseram que a consequência da dificuldade em dizer não é a de que a criança para de pedir e um deles tenta uma conversa com a criança sem muito sucesso.

Nesse grupo de educadores, os pais justificam as "dificuldades de demonstrar carinho" $(n=3)$ afirmando que o filho está mais velho e não é mais uma criança $(n=1)$, ou porque a relação com a criança tem um histórico de pouco diálogo $(n=1)$, podendo os pais até recusar um pedido de beijo do filho $(n=1)$. Dois participantes relataram que essa dificuldade acarreta sentimentos de desconforto. 


\section{DisCUSSÃo}

Os resultados descritos apontam as queixas mais frequentes trazidas pelos participantes a partir do Roteiro Semiestruturado: "criança é agressiva”, "criança não obedece às ordens dadas pelos pais", "criança apresenta comportamento de birra”, todos podendo ser classificados como externalizantes; e as queixas mais frequentes de dificuldades dos pais/cuidadores: "grita e/ou bate quando o filho emite comportamentos “indesejáveis'", "pai e mãe não concordam com relação à educação dos filhos (inconsistência entre os pais)", "falta de consistência da mãe/ pai/cuidador diante dos comportamentos da criança", "dificuldade em conversar/ comunicação com a criança” e "dificuldades em estabelecer limites".

De acordo com os resultados apresentados, a atitude dos participantes de gritar e/ou bater quando o filho emite comportamentos indesejáveis pode servir de modelo para que as crianças/adolescentes se comportem agressivamente, corroborando estudos que mostram que as práticas coercitivas dos pais podem fortalecer as mesmas respostas emitidas pelos filhos, em detrimento da consequenciação apropriada das respostas socialmente habilidosas (Brioso \& Sarria, 1995; Conte, 1997; Kaiser \& Hester, 1997; Kaplan, Sadock \& Grebb, 1997; Patterson, DeBaryshe \& Ramsey, 1989; Webster-Stratton, 1997). Na maioria dos casos descritos no presente trabalho, quando a criança apresenta um comportamento de bater, chutar ou gritar, os cuidadores agem de modo semelhante na intenção de conter tais respostas, ou seja, os pais/cuidadores gritam e batem em seus filhos quando estes se comportam de maneira indesejada. Diante disto cria-se um ciclo coercitivo (Webster-Stratton, 1997), mantido possivelmente por consequências reforçadoras negativas, à medida que, ao menos parte das vezes, os participantes conseguem parar a agressividade dos filhos ao gritar, os quais repetem o modelo e devem obter algum controle sobre o comportamento deles. De todo modo, os resultados alertam que tanto pais/cuidadores quanto filhos têm dificuldades em lidar com situações de contrariedade e os dados indicam que tenham baixo repertório de habilidades sociais, tais como comunicação e estabelecimento de limites, continuando a se comportar agressivamente, ainda que isto também traga punições.

Os resultados sugerem que o comportamento de birra dos filhos pode estar funcionalmente relacionado à inconsistência dos pais/cuidadores, pois, frequentemente, quando os pedidos das crianças/adolescentes são negados por eles, estes apresentam comportamentos de choro, grito, jogar-se no chão, insistindo nas suas necessidades; momentos em que os cuidadores acabam por ceder e atendem o que outrora fora negado, caracterizando, assim, a inconsistência do seu comporta- 
mento e oferecendo, aos filhos, reforçador intermitente, bastante poderoso na manutenção de respostas.

A queixa dos pais de que as crianças/adolescentes não obedecem às ordens dadas por eles pode ser reflexo das dificuldades que estes apresentam em estabelecer limites aos comportamentos dos filhos. Esta situação possivelmente está relacionada com a dificuldade de comunicação também relatada pelos cuidadores, pois, como afirmam Bolsoni-Silva e Marturano (2002), essa habilidade possibilita o estabelecimento de limites, favorecendo uma interação social positiva com o filho. Segundo Skinner ([1953] 1993), o uso de agressão verbal e/ou física para estabelecer limites também pode não resolver o problema de comportamento a médio e longo prazo e pode levar a ressentimentos e dificuldades na relação de amizade entre os pais e filhos, o que parece concordar com os dados aqui mencionados, sobretudo na dificuldade de expressar afeto aos filhos.

Bolsoni-Silva (2003) e Cowan, Cohn, Cowan e Pearson (1996) mostram que quando os pais são socialmente habilidosos, demonstrando carinho através de contato físico e conversando com os filhos, eles apresentam menos riscos quanto ao surgimento de problemas de comportamento e agem de maneira habilidosa em suas relaçóes interpessoais. $\mathrm{O}$ presente estudo encontrou que, ao expressar sentimentos negativos de modo não habilidoso, os pais são modelo para que as crianças reajam de modo semelhante, apresentando comportamentos não habilidosos ativos, tais como agressividade, gritar, bater e espernear. Estes comportamentos não contribuem para o estabelecimento de vínculos afetivos entre os pais e seus filhos, assim como apontado por Bolsoni-Silva e Marturano (2002). Tais conclusões vão ao encontro dos estudos de Brioso e Sarria (1995), Conte (1997), Kaiser e Hester (1997), Kaplan, Sadock e Grebb (1997), Patterson, DeBaryshe e Ramsey (1989), Webster-Stratton (1997), que reiteram a hipótese de haver relação entre as variáveis repertório comportamental de pais e problemas de comportamento dos filhos.

\section{CONSIDERAÇÕES FINAIS}

Este artigo procurou caracterizar repertórios de pais e filhos quanto às queixas que motivam a procura por atendimento na realidade brasileira, visto que é possível observar uma lacuna em estudos desse gênero no campo das Habilidades Sociais Educativas Parentais. Os dados indicam necessidade de os psicólogos atentarem para as queixas referidas com o objetivo de realizar um trabalho preventivo e interventivo junto às famílias que procuram ajuda, uma vez que os estudos já citados anteriormente (Brioso \& Sarria, 1995; Bolsoni-Silva \& Marturano, 2002; 
Bolsoni-Silva, \& cols., 2003; Conte, 1997; Cowan \& cols., 1996; Kaiser \& Hester, 1997; Kaplan, Sadock \& Grebb, 1997; Patterson, DeBaryshe \& Ramsey, 1989; Webster-Stratton, 1997) mostram o quanto as habilidades sociais educativas dos pais são imprescindíveis para um desenvolvimento saudável das relações entre pais e filhos, podendo causar sérios problemas na vida adulta e infantil das crianças quando são deficitárias. O manejo inefetivo dos pais, além de poder levar a sérios problemas de comportamento, também promove falhas no desenvolvimento de comportamentos sociais positivos e comunicativos da criança, que formam a base para a interação positiva com colegas e outros adultos (Kaiser \& Hester, 1997). Assim, verifica-se que quando os pais e as mães são socialmente habilidosos os filhos apresentam menos riscos quanto ao surgimento de problemas de comportamento (Bolsoni-Silva, 2003).

Neste sentido, estudos futuros nesta área, bem como intervenções junto a pais e cuidadores, podem melhorar as interações sociais e contribuir para o avanço das pesquisas. A orientação de pais possibilita instrumentá-los com habilidades necessárias para lidar com as dificuldades da criança, o que pode reduzir as queixas de problemas de comportamento e promover um relacionamento mais satisfatório entre pais e filhos. Novas pesquisas devem ser conduzidas de forma a utilizar outros instrumentos de avaliação, incluindo a observação.

Os resultados obtidos com a presente pesquisa indicam a necessidade de os serviços oferecidos em clínicas-escola, no que se refere à orientação de pais e intervenção com crianças/adolescentes, atentarem não apenas para a redução de problemas externalizantes e de práticas educativas negativas, mas que ampliem o serviço para: a) avaliar funcionalmente o repertório de pais e filhos, garantindo na intervenção o atendimento a demandas individuais, além das grupais; b) avaliar e conduzir a intervenção a partir também de repertórios positivos de pais e filhos; por exemplo, as crianças, neste estudo, expressam afeto e os pais são capazes de conversar quando as crianças buscam atenção, além disso também encorajam os filhos a enfrentar os medos presentes diante de interações sociais diversas; c) focar os sentimentos dos pais, tanto os positivos quanto os negativos, que favorecem o vínculo terapeuta-cliente e ajudam a compreender as contingências em operação; d) avaliar também os comportamentos internalizantes das crianças e os comportamentos não habilidosos passivos dos pais, de forma a intervir adequadamente para as suas superações; e) ensinar o comportamento de autocontrole que é prérequisito para comportamentos mais complexos, como agir de forma socialmente habilidosa diante de desobediência e agressividade dos filhos; f) ensinar consistência entre as próprias práticas e entre os diferentes agentes educativos, o que 
remete a um trabalho direcionado também aos conflitos conjugais, sobretudo os que interferem diretamente na educação dos filhos.

\section{REFERÊNCIAS BIBLIOGRÁFICAS}

Achenbach, T. M. \& Edelbrock, C. S. (1979). The child behavior profile: II. Boys aged 12-16 and girls aged 6-11 and 12-16. Journal of Consulting and Clinical Psychology, 47(2), 223-233.

Bolsoni-Silva, A. T. (2003). Habilidades sociais educativas, variáveis contextuais e problemas de comportamento: comparando pais e mães de escolares. Tese de Doutorado, Departamento de Psicologia, Universidade de São Paulo.

Bolsoni-Silva, A. T.; Bitondi, F. \& Marturano, E. M. (2008). Intervenção em grupo para pais: a importância do diagnóstico comportamental individual. Em Cavalcanti, R. (org.). Análise do comportamento: avaliação e intervenção (pp. 79-100). São Paulo: Roca.

Bolsoni-Silva, A. T. \& Del Prette, A. (2002). O que os pais falam sobre suas habilidades sociais e de seus filhos? Revista das Faculdades de Educação, Ciências e Letras de Psicologia Padre Anchieta: Argumento, 3 (7), 71-86.

. (2003). Problemas de comportamento: um panorama da área. Revista Brasileira de Terapia Comportamental e Cognitiva, 5, 91-103.

Bolsoni-Silva, A. T.; Del Prette, A. \& Oishi, J. (2003). Habilidades sociais de pais e problemas de comportamento de filhos. Revista das Faculdades de Educação, Ciências e Letras de Psicologia Padre Anchieta: Argumento, 5 (9), 11-29.

Bolsoni-Silva, A. T. \& Marturano, E. M. (2002). Práticas educativas e problemas de comportamento: uma análise à luz das habilidades sociais. Estudos em Psicologia, 7 (2), 227 235.

(2006). A qualidade da interação entre pais e filhos e sua relação com problemas de comportamento de pré-escolares. Em Estudos sobre habilidades sociais e relacionamento interpessoal (pp. 89-104). São Paulo: Casa do Psicólogo.

Brioso, A. \& Sarria, E. (1995). Distúrbios de comportamento. Em Coll, C.; Palacios, J. \& Marchesi, A. (orgs.). Desenvolvimento psicológico e educação: necessidades educativas especiais e aprendizagem escolar (pp. 157-168), vol. 3. Porto Alegre: Artes Médicas.

Caballo, V. E. (1996). O treinamento em habilidades sociais. Em Caballo, V. E. (org.). Manual de técnicas de terapia e modificação do comportamento (pp. 361-398). São Paulo: Santos.

Cole, P. M.; Zanh-Wasler, C. \& Smith, K. D. (1994). Expressive control during a disappointment: variations related to preschoolers' behavior problems. Development Psychology, 30 (6), 835-846. 
Conte, F. C. (1997). Promovendo a relação entre pais e filhos. Em Delitti, M. (org.). Sobre comportamento e cognição (pp. 165-173). Santo André: Arbytes Editora.

Cowan, P. A.; Cohn, D. A.; Cowan, C. P. \& Pearson, J. L. (1996). Parent's attachment histories and children's externalizing and internalizing behaviors: exploring family systems models of linkage. Journal of Consulting and Clinical Psychology, 64 (1), 53-63.

D’Avila-Bacarji, K. M. G.; Marturano, E. M. \& Elias, L. C. S. (2005). Suporte parental: um estudo sobre crianças com queixas escolares. Psicologia em Estudo, 10 (1), 107-115. Maringá.

Del Prette, A. \& Del Prette, Z. A. P. (2001). Psicologia das relaçôes interpessoais: vivências para o trabalho em grupo. Petrópolis: Vozes.

Dishion, T. J. \& Andrews, D. W. (1995). Preventing escalation in problem behaviors with high-risk young adolescents: immediate and 1-year outcomes. Journal of Consulting and Clinical Psychology, 63 (4), 538-548.

Gomide, P. I. C. (2006). Inventário de estilos parentais. Modelo teórico: manual de aplicação, apuração e interpretação. Petrópolis: Vozes.

Graminha, S. S. V. (1994). Problemas emocionais comportamentais em uma amostra de escolares: incidência em função do sexo e idade. Psico, 25, 44-74.

Kaiser, A. P. \& Hester, P. P. (1997). Prevention of conduct disorder through early intervention: a social-communicative perspective. Behavioral Disorders, 22 (3), 117130.

Kaplan, H. I.; Sadock, B. J. \& Grebb, J. A. (1997). Compêndio de psiquiatria: ciências do comportamento e psiquiatria clínica, $7^{\text {a }}$ edição. Porto Alegre: Artes Médicas.

Kilgore, K.; Snyder, J. \& Lentz, C. (2000). The contribution of parental discipline, parental monitoring and school risk to early-onset conduct problems in African boys and girls. Developmental Psychology, 36 (6), 835-845.

Jouriles, E. N. \& Norwood, W. D. (1995). Physical aggression toward boys and girls in families characterized by the battering of women. Journal of Family Psychology, 9 (1), 69-78.

Marinho, M. L. \& Silvares, E. F. M. (1996). Solução de conflitos e percepção de ajustamento infantil em pais de crianças com ou sem encaminhamento psicoterápico. Estudos de Psicologia, 13, 23-31.

Marturano, E. M.; Parreira, V. L. C. \& Benzoni, S. A. G. (1997). Crianças com queixa de dificuldade escolar: avaliação das mães através da Escala Comportamental Infantil A2 de Rutter. Estudos de Psicologia, 14 (3), 3-15.

Psic. Clin., Rio De Janeiro, vol.21, N.1, P.169 - 184, 2009 
Patterson, G. R.; DeBaryshe, B. D. \& Ramsey, E. (1989). A developmental perspective on antisocial behavior. American Psychologies, 44 (2), 329-335.

Pfiffner, L. \& McBurnett, K. (1997). Social skills training with parent generalization: treatment effects for children with attention deficit disorder. Journal of Consulting and Clinical Psychology, 65 (5), 749-757.

Romero, J. F. (1995). As relações sociais das crianças com dificuldades de aprendizagem. Em Coll, C.; Palácios, J. \& Marchesi, A. (orgs.). Desenvolvimento psicológico e educação: necessidades educativas especiais e aprendizagem escolar (pp. 71-82), vol. 3. Porto Alegre: Artes Médicas.

Rosa, L. T. B.; Garcia, R. M.; Domingos, N. A. M. \& Silvares, E. F. M. (2001). Caracterização do atendimento psicológico prestado por um serviço de psicologia a crianças com dificuldades escolares. Estudos de Psicologia, 17 (13), 5-15.

Ruma, P. R.; Burke, R. V. \& Thompson, R. W. (1996). Group parent training: is it effective for children of all ages? Behavior Therapy, 27, 159-169.

Sanders, M. R.; Markie-Dadds, C.; Tully, L. A. \& Bor, W. (2000). The Triple P-Positive Parenting Program: a comparison of enhanced, standard, and self-directed behavioral family intervention for parents of children with early onset conduct problems. Journal of Consulting and Clinical Psychology, 68 (4), 624-640.

Santos, M. A. (1990). Caracterização da clientela de uma clínica psicológica da Prefeitura de São Paulo. Arquivos Brasileiros de Psicologia, 42 (2), 79-94.

Silva, A. T. B. (2000). Problemas de comportamento e comportamentos socialmente adequados: sua relação com as habilidades sociais educativas de pais. Dissertação de Mestrado, Departamento de Psicologia, Universidade Federal de São Carlos.

Skinner, B. F. (1953/1993). Ciência e comportamento humano. São Paulo: Martins Fontes.

Weber, L. N. D.; Prado, P. M.; Viezzer, A. P. \& Branderburg, O. J. (2004). Identificação de estilos parentais: o ponto de vista dos pais e dos filhos. Psicologia: Reflexão e Crítica, 17 (3), 323-331.

Webster-Stratton, C. (1997). Early intervention for families of preschool children with conduct problems. Em Guralnick, M. J. (org.). The effectiveness of early intervention (pp. 429-453). Baltimore: Paul H. Brookes Publishing Co. 
AneXo

Tabela 1: Frequência dos comportamentos externalizantes, internalizantes e outros

\begin{tabular}{|c|c|c|}
\hline Categorias & Comportamento & $\begin{array}{l}\text { Frequência } \\
\text { Absoluta }\end{array}$ \\
\hline \multirow{7}{*}{ Externalizantes } & \multirow{7}{*}{$\begin{array}{l}\text { Criança é agressiva } \\
\text { Criança não obedece às ordens dadas pelos pais } \\
\text { Comportamento de birra } \\
\text { Criança faz chantagens com mãe/pai } \\
\text { Criança tem comportamentos auto-lesivos } \\
\text { Criança conta mentiras para os pais }\end{array}$} & 28 \\
\hline & & 21 \\
\hline & & 9 \\
\hline & & 6 \\
\hline & & 6 \\
\hline & & 3 \\
\hline & & Total $=73$ \\
\hline \multirow{9}{*}{ Internalizantes } & \multirow{9}{*}{$\begin{array}{l}\text { Criança tem medo } \\
\text { Filho solicita atenção equivalente dos pais despendida ao irmão } \\
\text { Criança tem dificuldade de atenção na escola } \\
\text { Criança tem medo de ir para a escola } \\
\text { Dificuldades interpessoais da criança } \\
\text { Criança sofre de depressão } \\
\text { Criança não quer comer } \\
\text { Criança rói unha }\end{array}$} & 9 \\
\hline & & 7 \\
\hline & & 4 \\
\hline & & 3 \\
\hline & & 2 \\
\hline & & 2 \\
\hline & & 1 \\
\hline & & 1 \\
\hline & & Total $=29$ \\
\hline \multirow{3}{*}{$\begin{array}{l}\text { Outros } \\
\text { comportamentos }\end{array}$} & \multirow{3}{*}{$\begin{array}{l}\text { Criança tem comportamentos incompatíveis com a idade } \\
\text { Criança pega no peito de mulheres }\end{array}$} & 4 \\
\hline & & 2 \\
\hline & & Total $=6$ \\
\hline
\end{tabular}

Recebido em 28 de abril de 2008 Aceito para publicação em 23 de janeiro de 2009 